Military Technical College

Kobry El-Kobbah,

Cairo, Egypt

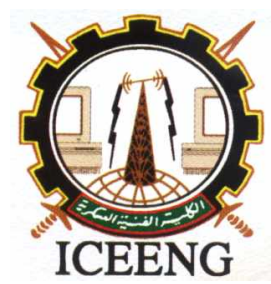

$6^{\text {th }}$ International Conference

on Electrical Engineering

ICEENG 2008

\title{
Dynamic modeling of permanent magnet synchronous motor using MATLAB - simulink
}

\author{
By \\ H. M. El Shewy* F. E. Abd Al Kader** M. M. El Kholy* A. El Shahat***
}

\section{$\underline{\text { Abstract: }}$}

Permanent Magnet Synchronous Motors (PMSM) are widely applied in industrial and robotic applications due to their high efficiency, low inertia and high torque - to volume ratio. So, this paper proposes two simulation dynamic models for ac Interior Permanent Magnet Synchronous Motor (IPMSM), and ac Surface Permanent Magnet Synchronous Motor (SPMSM) with the aid of MATLAB - Simulink. The modeling procedures are described and simulation results are presented. These dynamic models capable of predicting the machine's behaviour for this machine type. The model takes the core loss in its consideration, to show its effect on torque ripple. These non - linear models of the PMSM in $\mathrm{d}-\mathrm{q}$ reference frame are defined. The dynamic models are developed by coupling electrical equations and mechanical equations of the PMSM. All simulation results are presented for all machine's variable characteristics. The validity of our model here is verified using $\mathrm{V} \backslash \mathrm{f}$ control, at various frequencies values. These models will be used in future, in sensorless speed control.

\section{Keywords:}

PM Synchronous Motor, MATLAB - Simulink and dynamic modeling

* $\quad$ Faculty of Engineering, Zagazig University, Zagazig, Egypt

** Faculty of Engineering, Menofia University, Menofia, Egypt

*** Faculty of Pet.\& Mining Engineeing, Suez Canal University, Suez, Egypt. 


\section{Introduction:}

PM motor drives have been a topic of interest for the last twenty years. Different authors have carried out modeling and simulation of such drives. In 1986 Sebastian, T., Slemon, G. R. and Rahman, M. A. [1] reviewed permanent magnet synchronous motor advancements and presented equivalent electric circuit models for such motors and compared computed parameters with measured parameters. Experimental results on laboratory motors were also given. In 1986 Jahns, T.M., Kliman, G.B. and Neumann, T.W. [2] discussed that interior permanent magnet (IPM) synchronous motors possessed special features for adjustable speed operation which distinguished them from other classes of ac machines. They were robust high power density machines capable of operating at high motor and inverter efficiencies over wide speed ranges, including considerable range of constant power operation. In 1988 Pillay and Krishnan, R. [3], presented PM motor drives and classified them into two types such as permanent magnet synchronous motor drives (PMSM) and brushless dc motor (BDCM) drives. As an extension of his previous work, Pillay, P. and Krishnan, R. in 1989 [4] presented the permanent magnet synchronous motor (PMSM) which was one of several types of permanent magnet ac motor drives available in the drives industry. Particular attention was paid to the motor torque pulsations and speed response and experimental verification of the drive performance were given. Morimoto, S., Tong, Y., Takeda, Y. and Hirasa, T. in 1994 [5], in their paper aimed to improve efficiency in permanent magnet (PM) synchronous motor drives. The controllable electrical loss which consisted of the copper loss and the iron loss could be minimized by the optimal control of the armature current vector. The paper in 1997 by Wijenayake, A.H. and Schmidt, P.B. [6], described the development of a two-axis circuit model for permanent magnet synchronous motor (PMSM) by taking machine magnetic parameter variations and core loss into account. In 1997 Jang-Mok, K. and Seung-Ki, S. [7], proposed a novel fluxweakening scheme for an Interior Permanent Magnet Synchronous Motor (IPMSM). It was implemented based on the output of the synchronous PI current regulator reference voltage to PWM inverter. Bose, B. K., in 2001 [8], presented different types of synchronous motors and compared them to induction motors. The modeling of PM motor was derived form the model of salient pole synchronous motor. Bowen, C., Jihua, Z. and Zhang, R. in 2001 [9], addressed the modeling and simulation of permanent magnet synchronous motor supplied from a six step continuous inverter based on state space method. In 2002 Mademlis, C. and Margaris, N. [10], presented an efficiency optimization method for vector-controlled interior permanent-magnet synchronous motor drive. In 2004, Jian-Xin, X., Panda, S. K., Ya-Jun, P., Tong Heng, L. and Lam, B. H. [11] applied a modular control approach to a permanent-magnet synchronous motor (PMSM) speed control. Based on the functioning of the individual module, the modular approach enabled the powerfully intelligent and robust control modules to easily replace 
any existing module which did not perform well, meanwhile retaining other existing modules which were still effective. Araujo, R.E., Leite, A.V. and Freitas, D.S. in 1997 [12], mentioned the different simulation tools available and the benefits that were obtained by accelerating the process for the development of visual design concepts. Ong, C in 1998 [13], explained the need for powerful computation tools to solve complex models of motor drives. Macbahi, H. Ba-razzouk, A. Xu, J. Cheriti, A. and Rajagopalan, V. in 2000 [14], mentioned that a great number of universities and researchers used the MATLAB/SIMULINK software in the field of electrical machines because of its advantages such as user friendly environment, visual oriented programming concept, non-linear standard blocks and a large number of toolboxes for special applications. In 1997 Reece, J.H., Bray, C.W., Van Tol, J.J. and Lim, P.K. [15], discussed three possible computer simulation tools such as PSpice, HARMFLO and the Electromagnetic. Onoda, S. and Emadi, A. in 2004 [16], had developed a modeling tool to study automotive systems using the power electronics simulator (PSIM) software. PSIM was originally made for simulating power electronic converters and motor drives. This userfriendly simulation package was able to simulate electric/electronic circuits.

\section{Mathimatical Modeling:}

\subsection{Equivalent Circuit ( Without Core Loss )}

The presented equivalent circuit of fig.1, express about the dynamic equations of PMSM, but without taking the core loss into consideration.

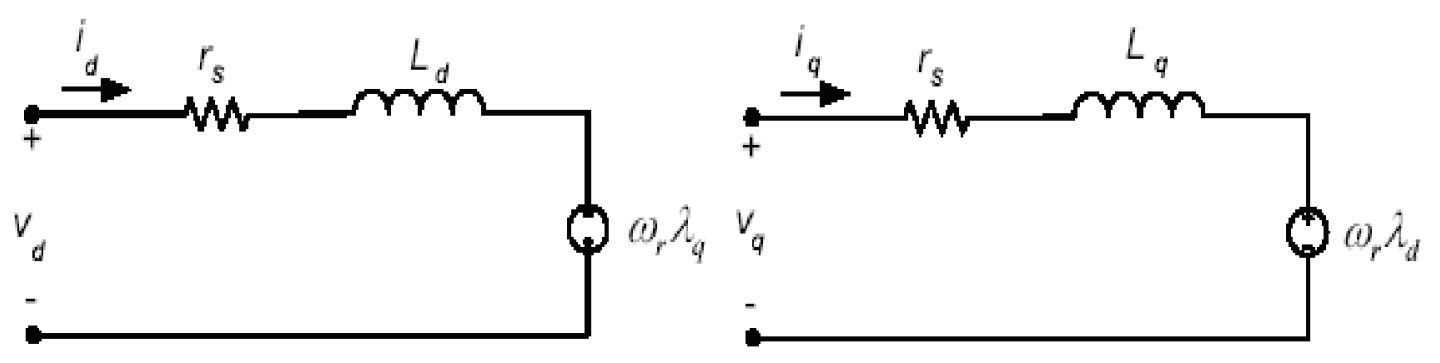

Figure (1) Equivalent Circuit without core loss

It should be notified that, all lower case symbols in introduce instantaneous values, not upper case as for steady state. 


\subsection{Dynamic equations of PMSM}

$\mathrm{v}_{\mathrm{q}}=\mathrm{r}_{\mathrm{s}} \mathrm{i}_{\mathrm{q}}+\rho\left(\lambda_{\mathrm{q}}\right)+\omega_{\mathrm{r}} \lambda_{\mathrm{d}}$

$\mathrm{v}_{\mathrm{d}}=\mathrm{r}_{\mathrm{s}} \mathrm{i}_{\mathrm{d}}+\rho\left(\lambda_{\mathrm{d}}\right)-\omega_{\mathrm{r}} \lambda_{\mathrm{q}}$

Where:

$\lambda_{\mathrm{q}}=\mathrm{L}_{\mathrm{q}} \mathrm{i}_{\mathrm{q}}$

$\lambda_{\mathrm{d}}=\mathrm{L}_{\mathrm{d}} \mathrm{i}_{\mathrm{d}}+\lambda_{\mathrm{m}}$

$\omega_{\mathrm{r}}$ : Electrical velocity of the rotor.

$\lambda_{m}$ : The flux linkage due to the rotor magnets linking the stator.

$\rho\left(\lambda_{\mathrm{m}}\right)=0, \lambda_{\mathrm{m}}=\mathrm{L}_{\mathrm{m}} \mathrm{i}_{\mathrm{fr}}$

$\rho$ : Operator $\frac{d}{d t}$

\subsection{Torque Equation:}

The electromagnetic torque is given by :

$\mathrm{T}_{\mathrm{e}}=\frac{3}{2} \frac{P}{2}\left(\lambda_{d} i_{q}-\lambda_{q} i_{d}\right)=\frac{3}{2} \frac{P}{2}\left(\lambda_{m} i_{q}+\left(L_{d}-L_{q}\right) i_{q} i_{d}\right)$

The electromechanical power $\mathrm{P}_{\mathrm{em}}=\omega_{\mathrm{rm}} \mathrm{T}_{\mathrm{e}}=\frac{3}{2} \omega_{\mathrm{r}}\left(\lambda_{\mathrm{d}} \mathrm{i}_{\mathrm{q}}-\lambda_{\mathrm{q}} \mathrm{i}_{\mathrm{d}}\right)$

$$
\omega_{\mathrm{r}}=\frac{P}{2} \omega_{\mathrm{rm}}
$$

Where :

$\mathrm{P} \quad$ : No of poles

$\omega_{\mathrm{rm}}:$ Mechanical velocity of the rotor.

The general mechanical equation for the motor is:

$\mathrm{T}_{\mathrm{e}}=\mathrm{T}_{1}+\mathrm{T}_{\mathrm{d}}+\mathrm{B} \omega_{\mathrm{rm}}+\mathrm{J} \rho \omega_{\mathrm{rm}}$

B : Viscous frictions coefficient

$\mathrm{J}$ : Inertia of the shaft and the load system

$\mathrm{T}_{\mathrm{d}}$ : Dry friction

$\mathrm{T}_{1}$ : Load torque

\subsection{Equivalent Circuit ( With Core Loss )}

This section considers the effect of core loss on the various performance characteristics 
equations.

$\mathrm{i}_{\mathrm{ds}}, \mathrm{i}_{\mathrm{qs}}: \mathrm{d}, \mathrm{q}$ axes stator currents.

$\mathrm{i}_{\mathrm{d}}, \mathrm{i}_{\mathrm{q}}: \mathrm{d}, \mathrm{q}$ axes stator currents.

$\mathrm{i}_{\mathrm{dc}}, \mathrm{i}_{\mathrm{qc}}: \mathrm{d}$, $\mathrm{q}$ axes core loss currents components.
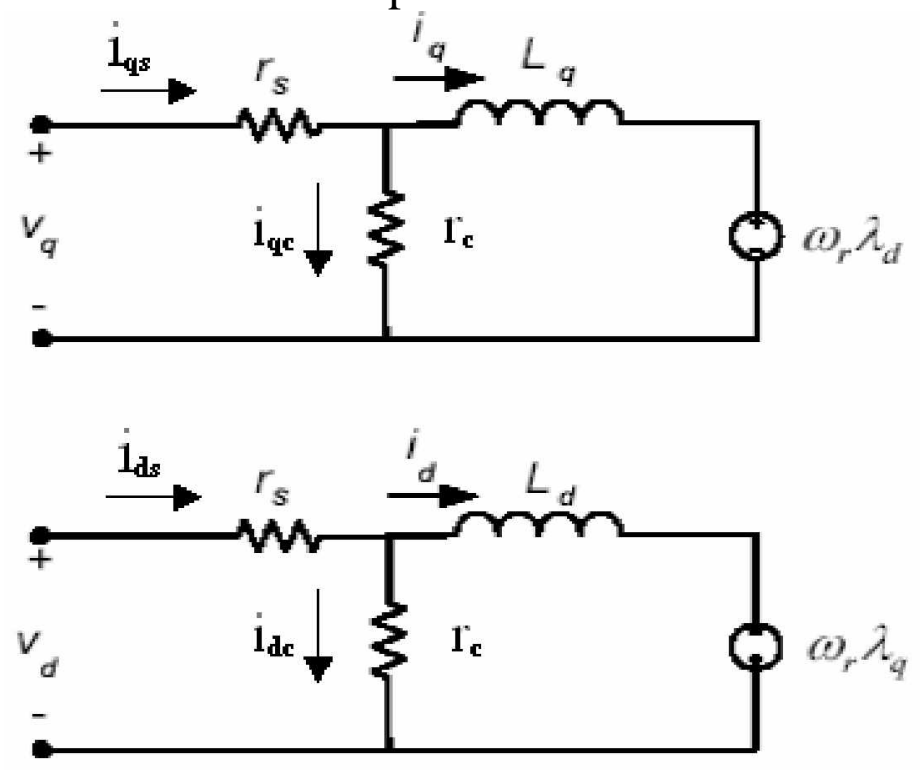

Figure (2) Equivalent Circuit with Core loss

$\mathrm{v}_{\mathrm{q}}=\mathrm{r}_{\mathrm{s}} \mathrm{i}_{\mathrm{q}}+\frac{\left(r_{s}+r_{c}\right)}{r_{c}} \rho\left(\lambda_{\mathrm{q}}\right)+\frac{\left(r_{s}+r_{c}\right)}{r_{c}} \omega_{\mathrm{r}} \lambda_{\mathrm{d}}$

$\mathrm{v}_{\mathrm{d}}=\mathrm{r}_{\mathrm{s}} \dot{\mathrm{i}}_{\mathrm{d}}+\frac{\left(r_{s}+r_{c}\right)}{r_{c}} \rho\left(\lambda_{\mathrm{d}}\right)-\frac{\left(r_{s}+r_{c}\right)}{r_{c}} \omega_{\mathrm{r}} \lambda_{\mathrm{q}}$

The expression of $\mathrm{T}_{\mathrm{e}}$ is the same as without core resistance, this implies that the effect of this resistance does not appear directly in this expression but as its effect in $\lambda_{d}$ also $\lambda_{q}$ and consequently on $\mathrm{T}_{\mathrm{e}}$.

\subsection{Dynamic Simulation}

This dynamic simulation of PMSM is done with the aid of SIMULINK in MATLAB package.

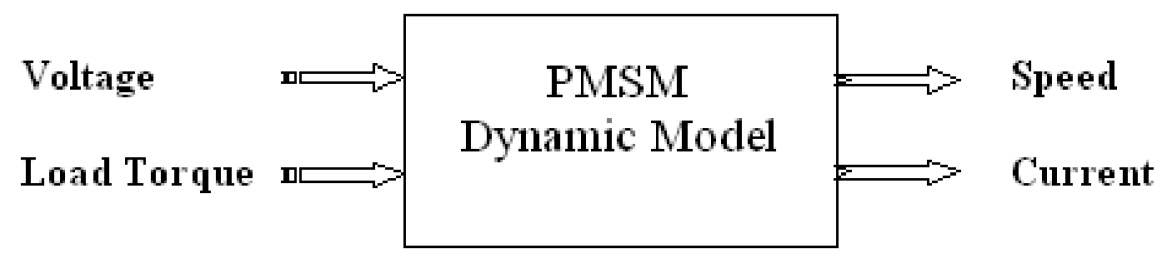

Figure (3) PMSM Model Block 
Fig. 3, presents a block for the PMSM in which, the voltage and load torque are considered as inputs, with the speed and current as outputs.

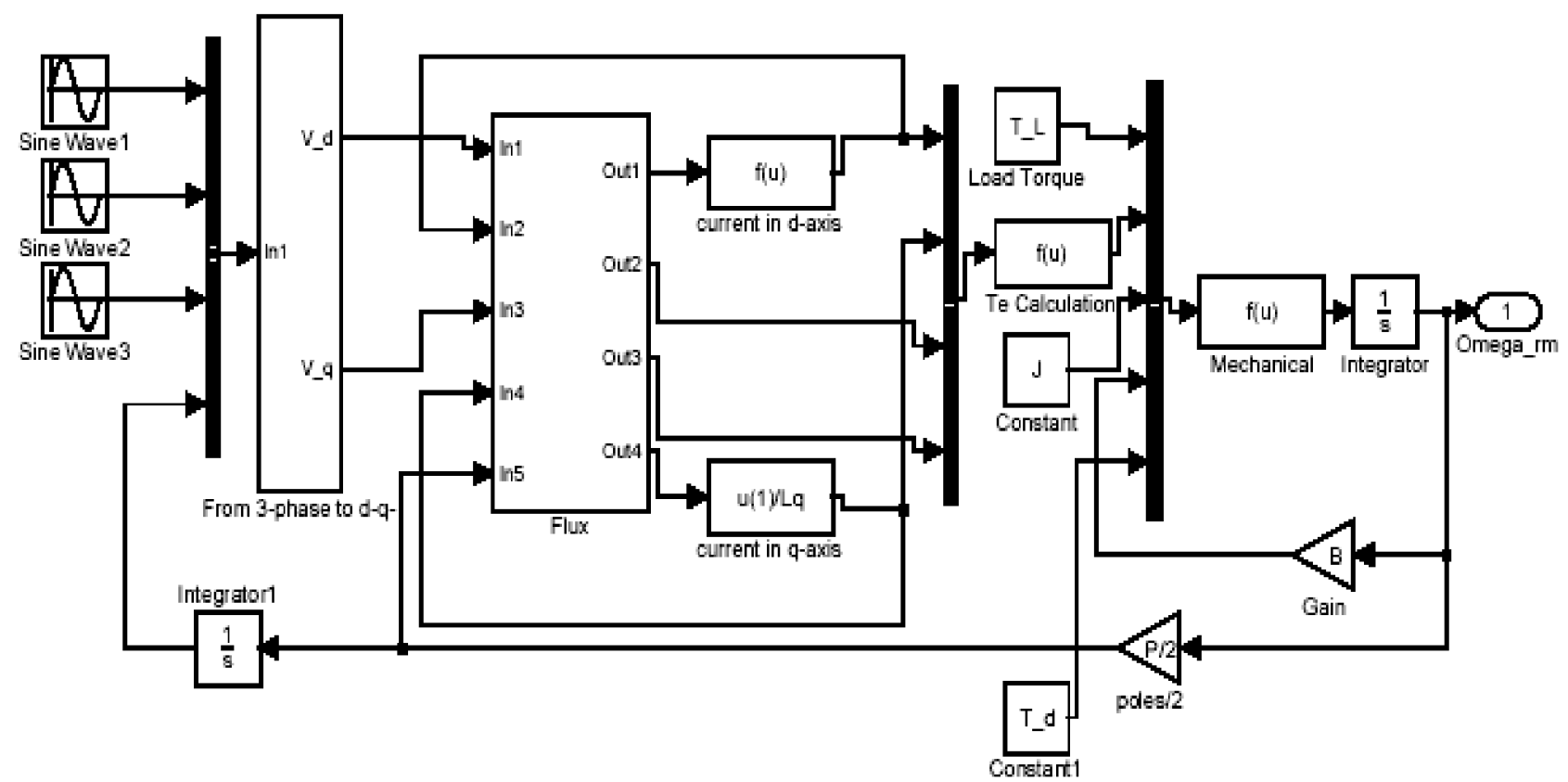

Figure (4) Permanent Magnet Synchronous Motor Model

Fig. 4, introduces the PMSM more detailed model with the aid of simulink, its details are described below.

\subsubsection{From 3 - phase to $d$ - q. Voltages}

The $1^{\text {st }}$ main part, which shown in fig.5, concerns with the Park's transformation (written below) from 3 - phase voltages ( $a b c$ ) into $d-q$ voltages components.

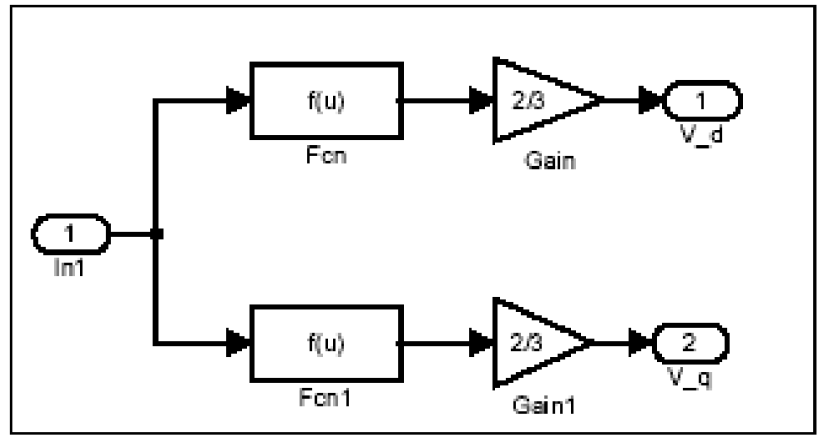

Figure (5) abc to dq voltages transformation 


\section{Park's Transformation:}

$$
\left[\begin{array}{l}
v_{a} \\
v_{d} \\
v_{0}
\end{array}\right]=\frac{2}{3}\left[\begin{array}{ccc}
\cos (\theta) & \cos \left(\theta-\frac{2 \pi}{3}\right) & \cos \left(\theta+\frac{2 \pi}{3}\right) \\
\sin (\theta) & \sin \left(\theta-\frac{2 \pi}{3}\right) & \sin \left(\theta+\frac{2 \pi}{3}\right) \\
\frac{1}{2} & \frac{1}{2} & \frac{1}{2}
\end{array}\right] \cdot\left[\begin{array}{c}
v_{a} \\
v_{b} \\
v_{c}
\end{array}\right]
$$

\subsection{2 d - q. Flux}

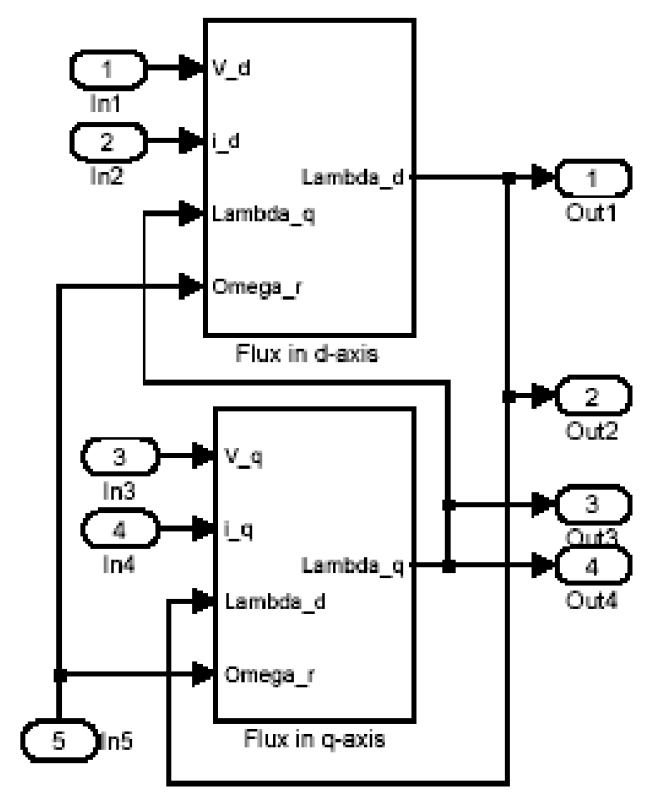

Figure (6) Flux

In fig. 6 the flux in $\mathrm{d}-$ axis and the flux in $\mathrm{q}-$ axis are presented with the blocks inputs and outputs. They come from the relations mentioned in the beginning of this chapter. The detailed block for $\mathrm{d}-$ axis flux is introduced in fig. 7 , and $\mathrm{q}-$ axis flux block is presented in fig. 8 .

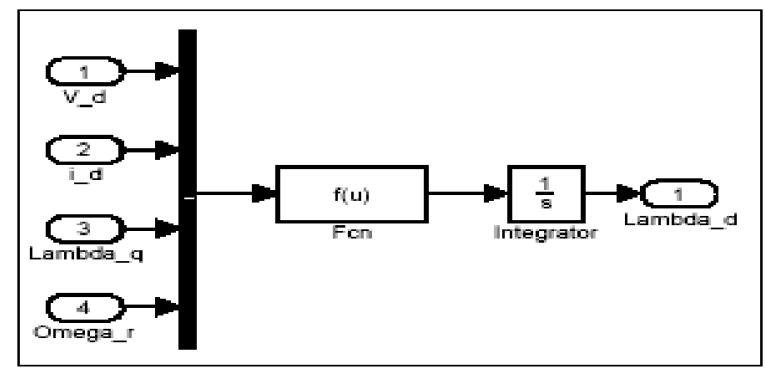

Figure (7) $d$-axis flux 


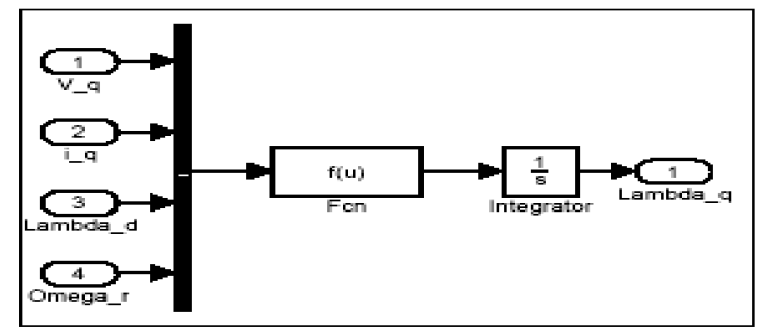

\subsection{3 d - q. Currents}

Figure (8) q-axis flux

Fig. 9, and fig. 10 introduce the relations for $\mathrm{d}-$ axis and $\mathrm{q}-$ axis currents obeying the relations introduced before.

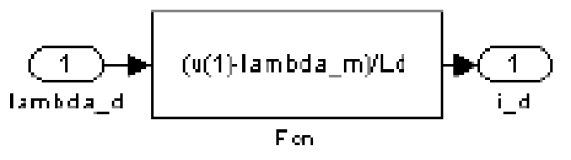

Figure (9) Current in $d$-axis

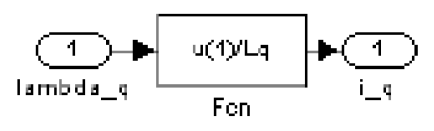

Figure (10) Current in $q$-axis

\subsubsection{The mechanical equation for the motor}

This equation is represented in simulink as illustrated in fig. 11.

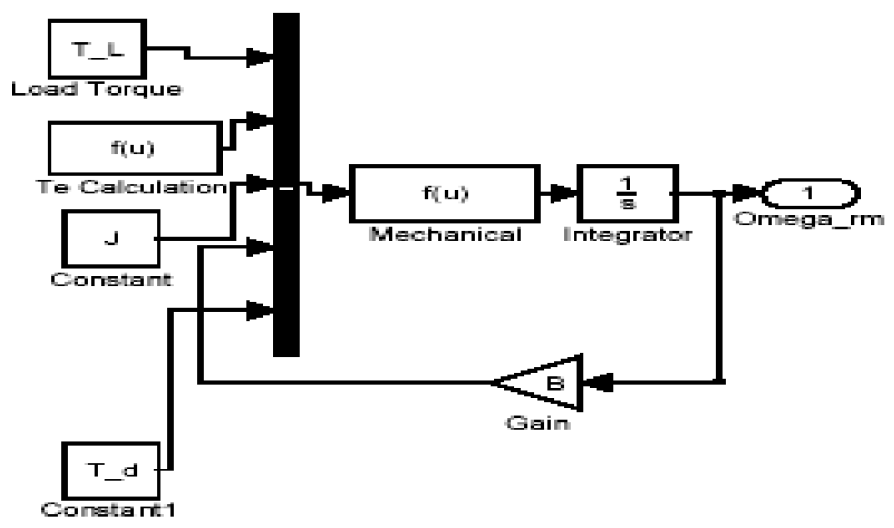

Figure (11) Mechanical equation of the motor. 


\section{Model Simulation Results:}

This section introduces some simulation performance of this model by using the scope to can see the various characteristics with the time. Also, in this section comparisons between the scope readings with and without taking core loss into our consideration in order to show the fadelity of taking it in this model.
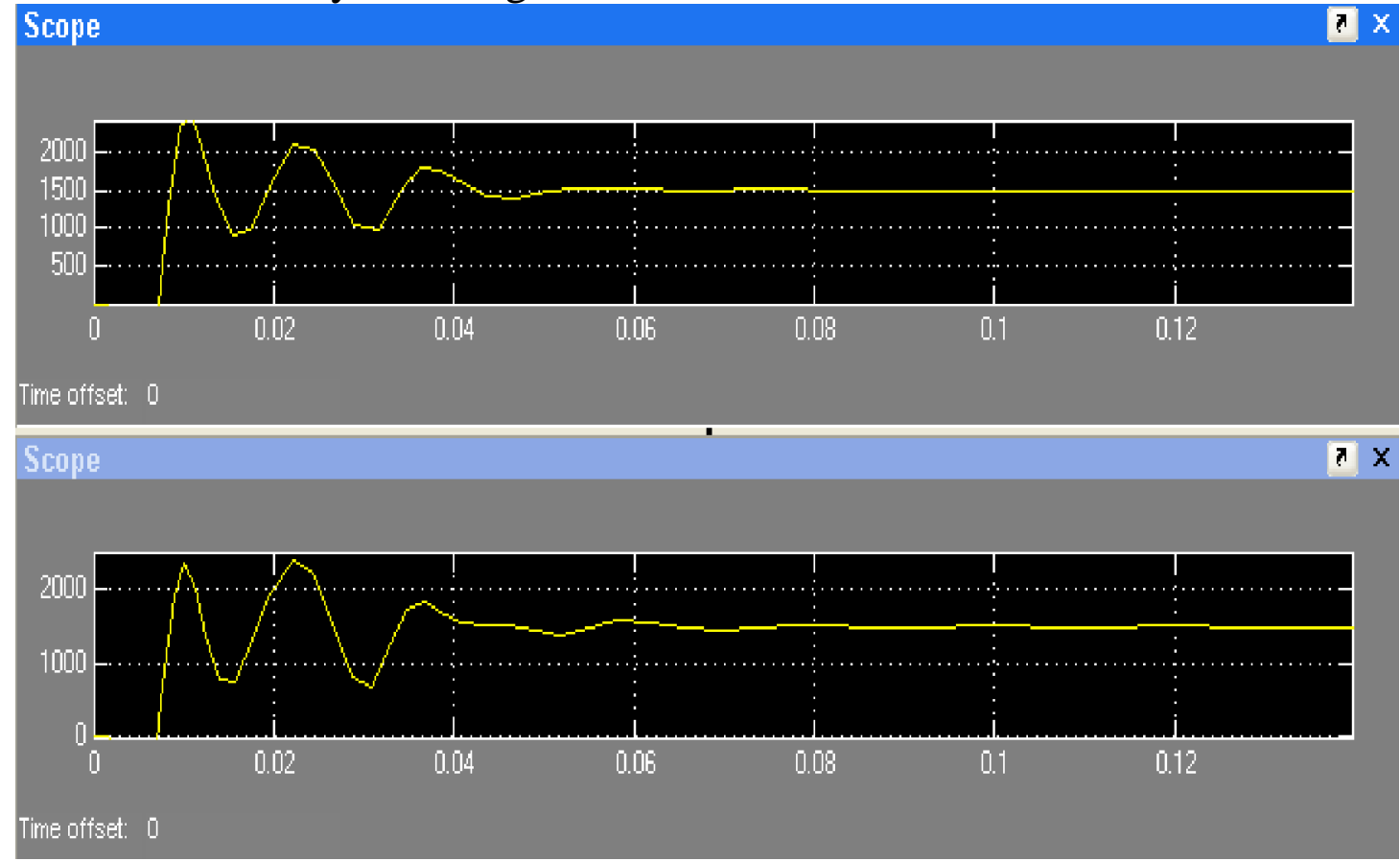

Figure (12) Comparison between speed (r.p.m) scope readings with and without taking core loss into consideration $(f=50 \mathrm{~Hz})$

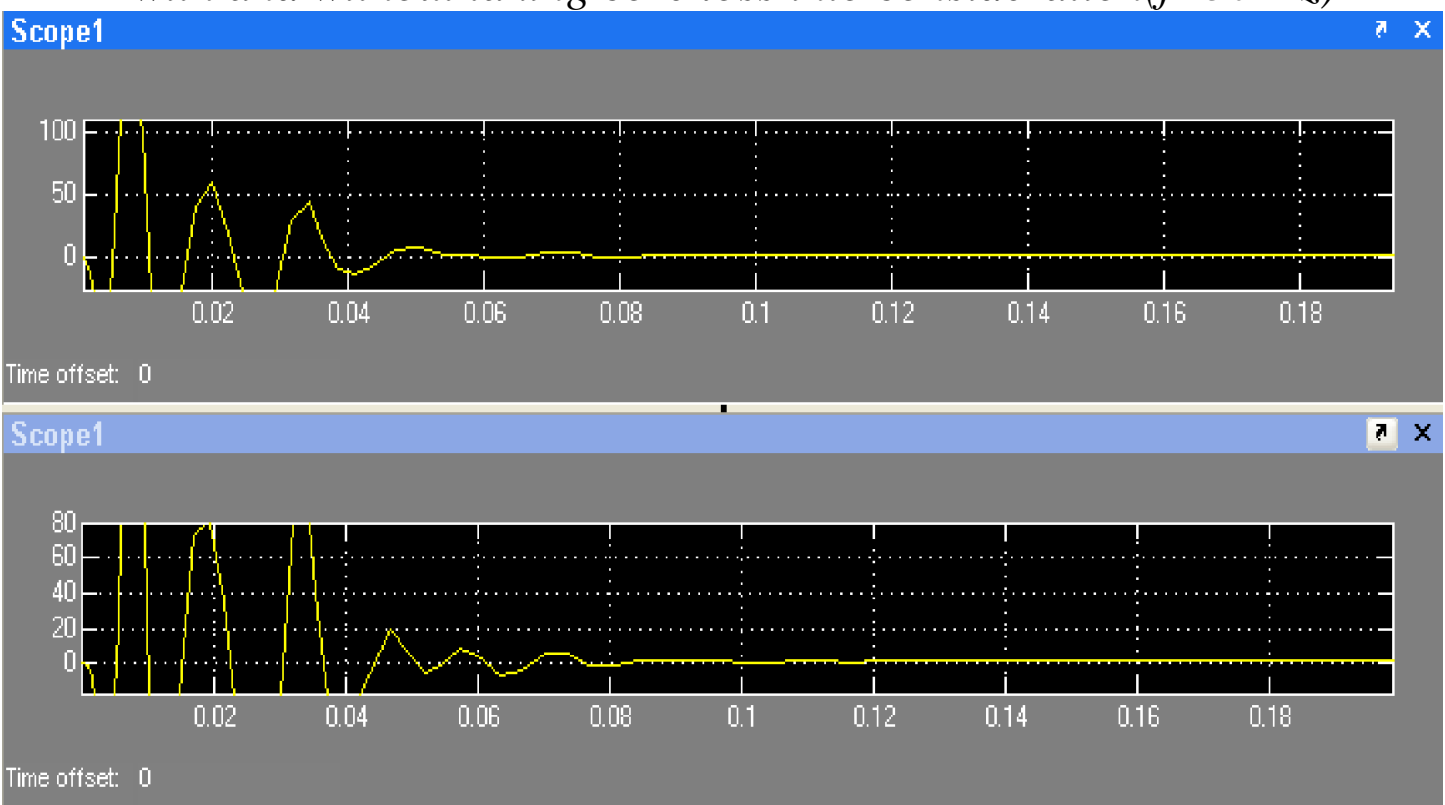

Figure (13) Comparison between Torque( $\mathrm{N} / \mathrm{m})$ scope readings with and without taking core loss into consideration. 
From these given scope readings (fig. 12 , fig. 13 ), the difference is clear between this model which implemented without core resistance and the other one taking the core loss into consideration in the ripples of their dynamice characteristics ( speed and torque ).

These figures affirm on the consideration of torque non-linearity Caused by ignoring core losses, as a drawback of most existing control strategies is that they rely on an electrical model of the machine that does not account for core losses. As speed increases a larger percentage of the input current is utilized in the generation of core losses. Obviously, this fraction of the input current does not contribute to the generation of torque. Therefore, the assumption that the entire input current generates torque at all speeds results in torque non-linearity as speed approaches the rated speed and beyond.

The following assumptions are made in this model:

- All motor parameters are assumed to be constant .

- Leakage inductances are zero

- Windage and friction are negligible

These previous dynamic model characteristics are taken for IPMSM parameters given as : $\mathrm{L}_{\mathrm{q}}=12.5 \mathrm{mH}, \mathrm{L}_{\mathrm{d}}=5.7 \mathrm{mH}, \lambda_{\mathrm{af}}=123$ mWeber-turns, $\mathrm{P}=4, \mathrm{R}_{\mathrm{s}}=1.2, \mathrm{R}_{\mathrm{c}}=416$ Ohms.

\section{Model Verification:}

The dynamic models implemented in this chapter could be verified by varying the frequency to can check the synchronous speed.

\subsection{V/f control ( variable frequency Verification )}

The V/f control is used mostly for simple variable speed applications like fans and pumps. This type of control has low cost and simple design, and is advantageous in the middle to high-speed range. A block diagram of this type of control can be represented as in the Figure 14.

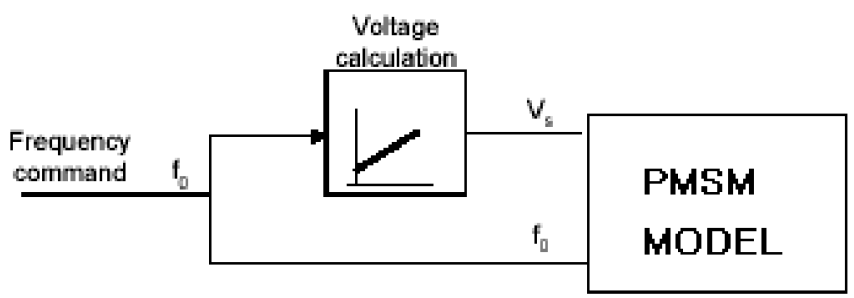

Figure (14) Block diagram of the V/f control. 
Driving a PMSM with V/f control is in fact an open loop control without position sensor (as V/f control in induction motor drive). This method keeps constant the ratio between the output frequency and the output voltage, in order to have a constant flux in the machine. Unlike the others types of control, V/f control method does not require high performance digital processing. The question here is how can this method of control apply on our model. It is more easier to construct a block for three phase power supply, instead of the another previously prepared by simulink which used before. This block comes to meet the requirements of such control method as shown in fig. 15 .

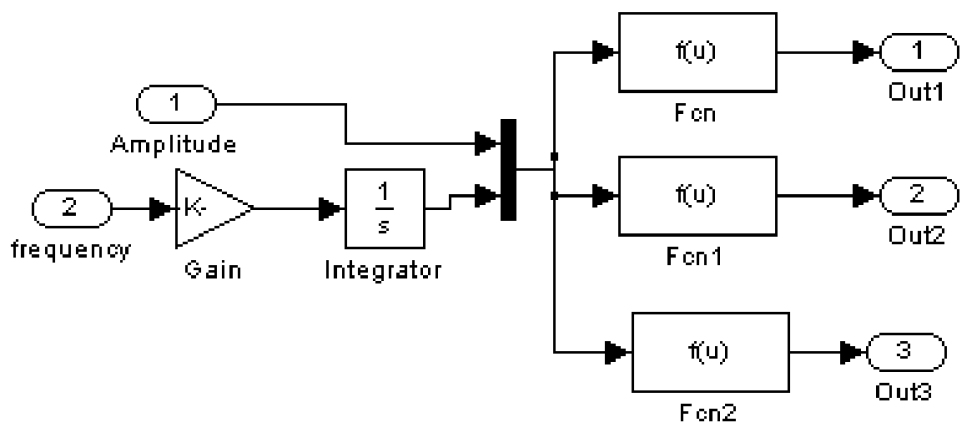

Figure (15) Three phase power supply

In this block, $\mathrm{Fcn}=\mathrm{u}(1) * \cos (\mathrm{u}(2)), \mathrm{Fcn} 1=\mathrm{u}(1) * \cos (\mathrm{u}(2)-(2 * \mathrm{pi} / 3))$

$$
\mathrm{Fcn} 2=\mathrm{u}(1) * \cos (\mathrm{u}(2)-(4 * \mathrm{pi} / 3))
$$

Also, Gain $=2 *$ pi

To change the frequency with the corresponding required voltage amplitude, another small block is attached as shown in fig. 16.

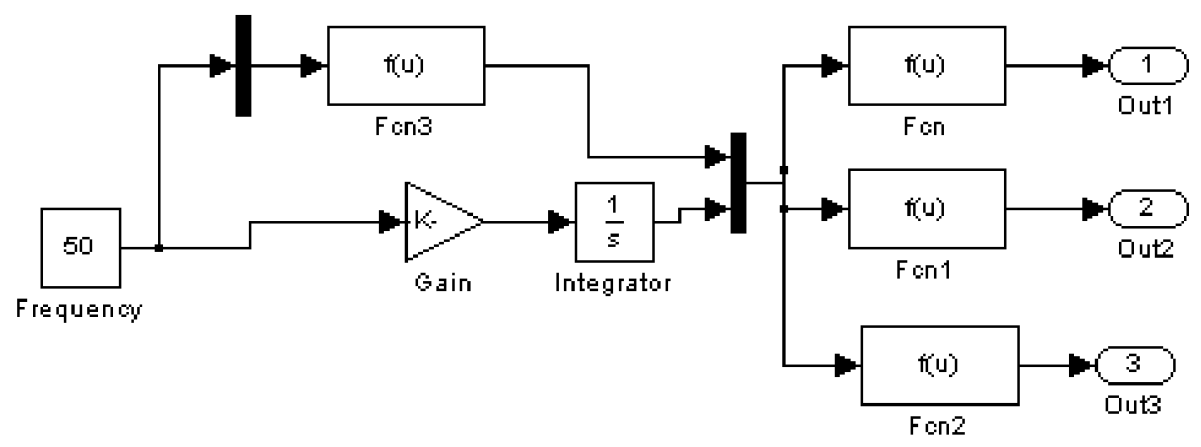

Figure (16) Modified block for v/f control. 


\subsection{Simulation Results ( $\mathrm{v} / \mathrm{f}$ )}

This section presents some simulation results for variable frequency under the pattern of $\mathrm{v} / \mathrm{f}$ constant.

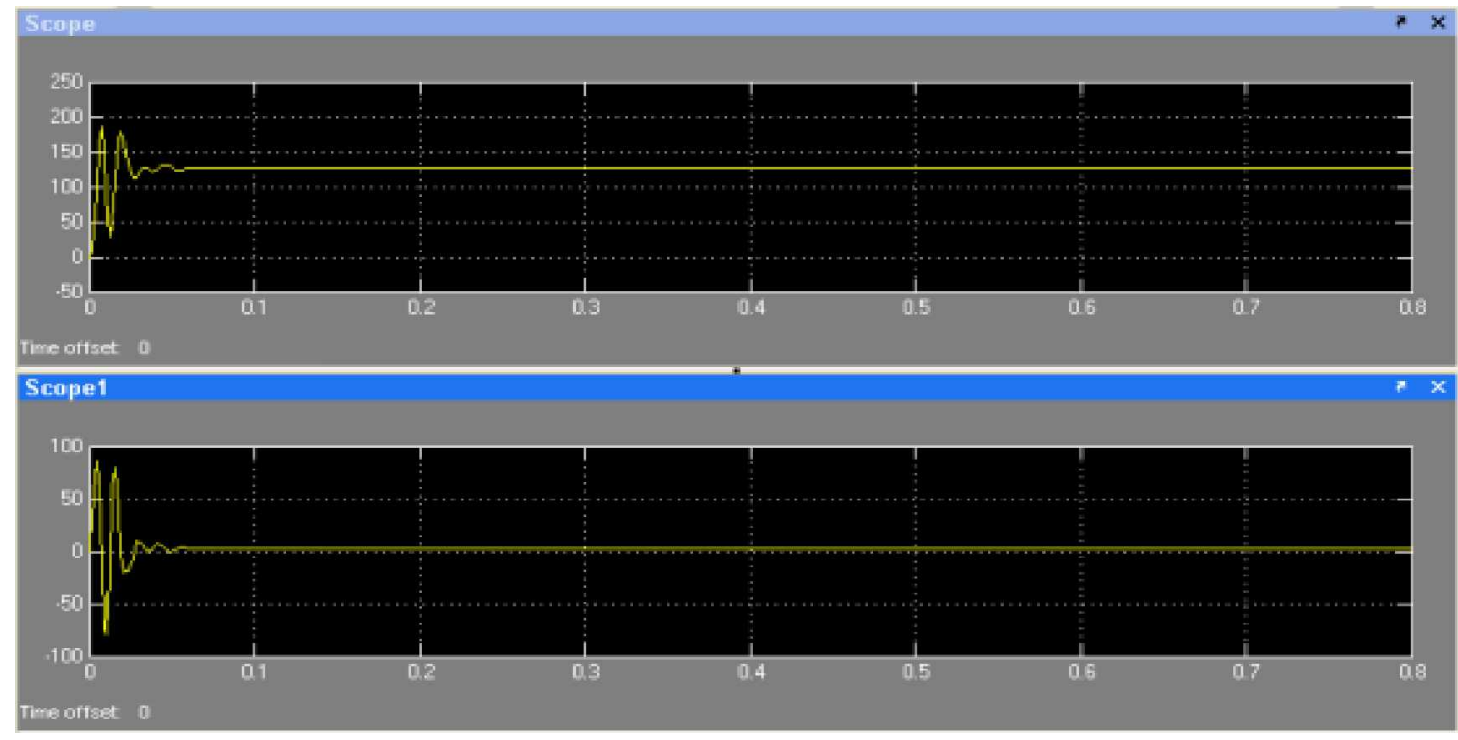

Figure (17) Speed (rads) and Torque ( $\mathrm{Nm}$ ) scope readings at $40 \mathrm{~Hz}$.

From fig. 17, its clear that the steady state value of the speed $=\mathrm{pi}^{*} 40 \mathrm{~Hz} \mathrm{rad} / \mathrm{sec}$, i.e. the mechanical speed value at this frequency.

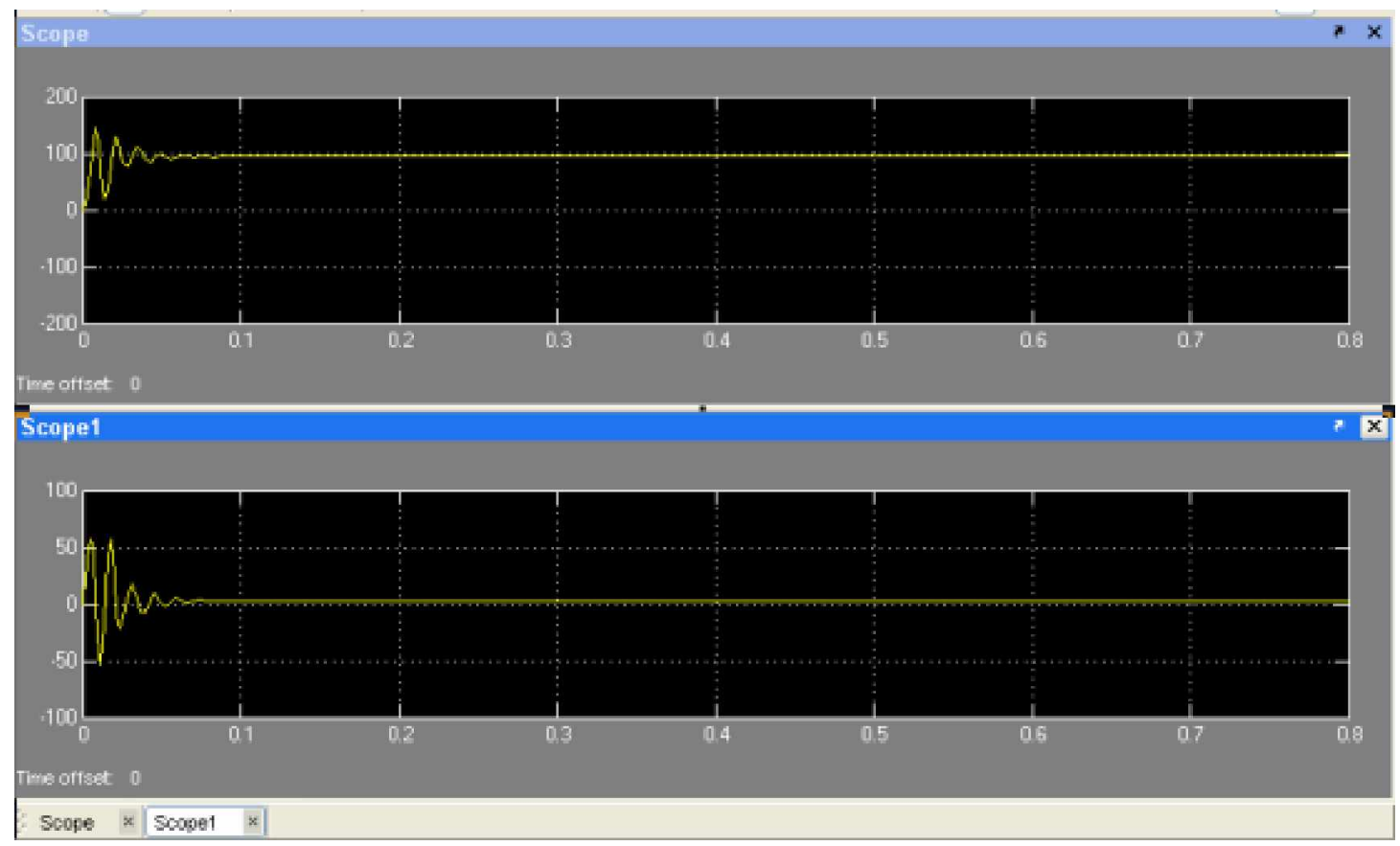

Figure (18) Speed and Torque scope readings at $30 \mathrm{~Hz}$ frequency. 


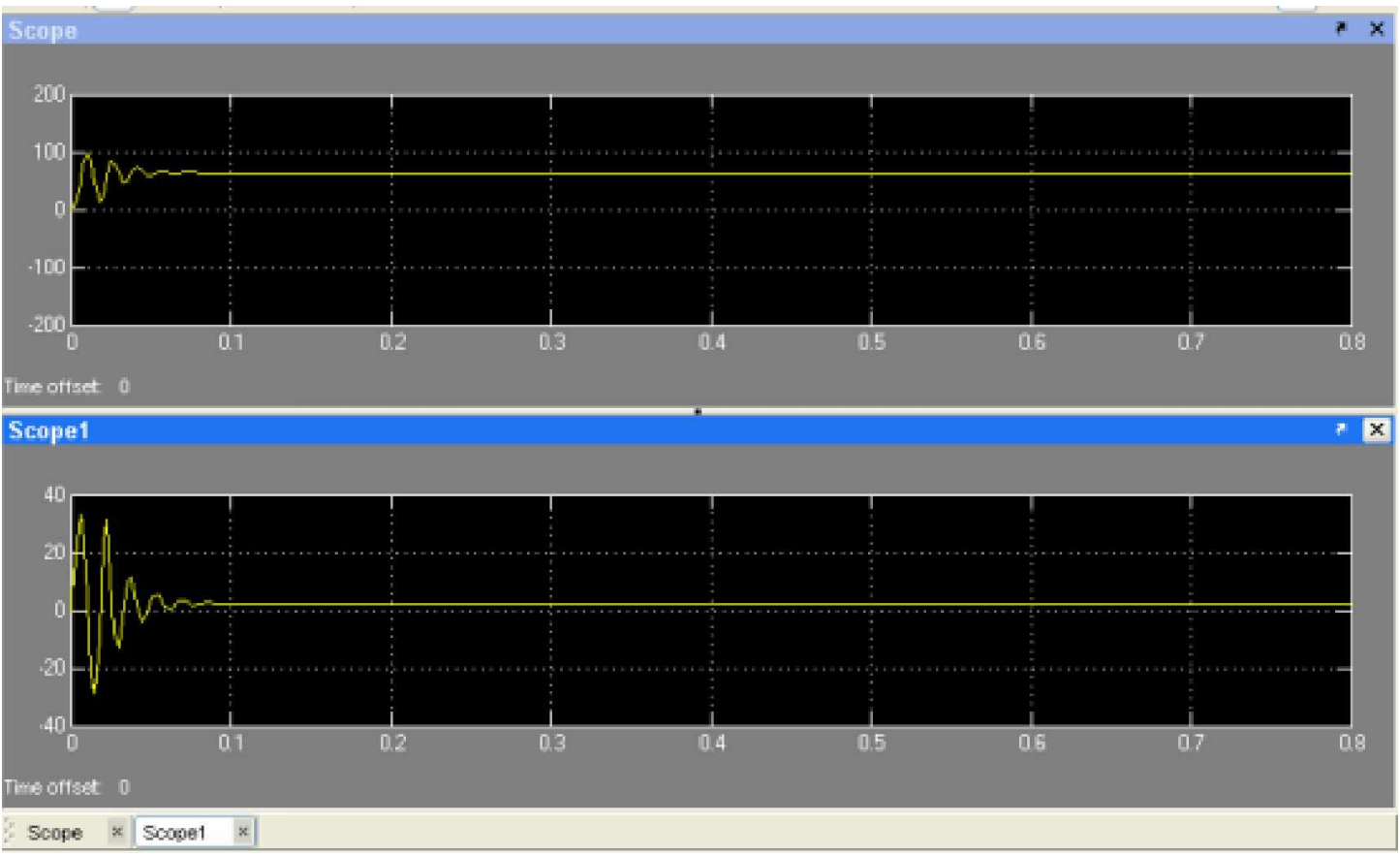

Figure (19) Speed and Torque scope readings at $20 \mathrm{~Hz}$ frequency.

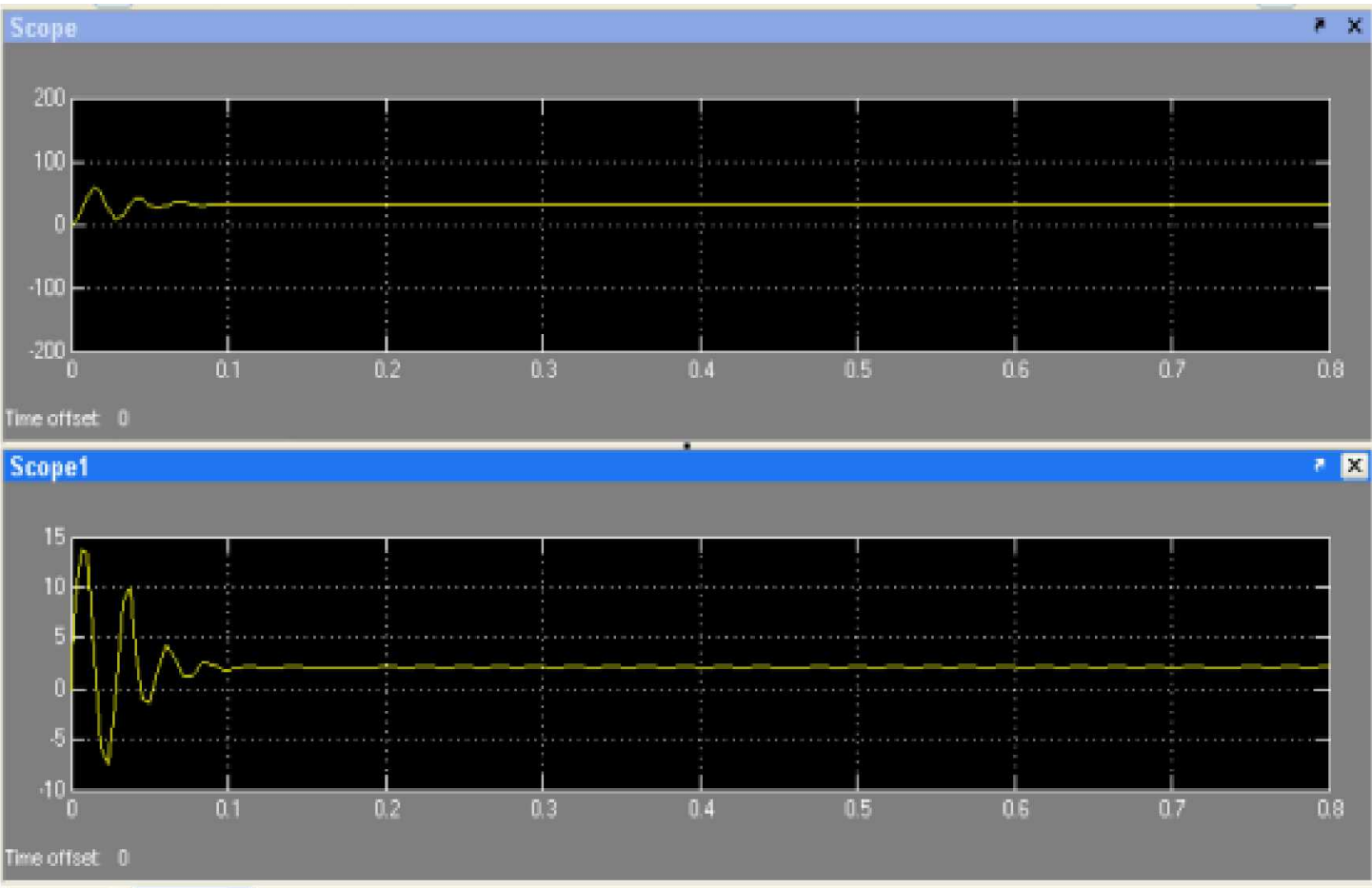

Figure (20) Speed and Torque scope readings at $10 \mathrm{~Hz}$ frequency. 
For all cases, it is notified that all the measured speed equal the desired mechanical ones under the variable corresponding frequencies.

\section{Dynamic simulation for SPMSM:}

This model depend on the following motor parameters.

$\mathrm{L}_{\mathrm{q}}=0.0115 \mathrm{H}, \mathrm{L}_{\mathrm{d}}=0.0115 \mathrm{H}, \lambda_{\mathrm{af}}=0.0283$ Weber-turns, $\mathrm{P}=4, \mathrm{R}_{\mathrm{s}}=6.8 \mathrm{ohm}, \mathrm{Vs}=200$ $\mathrm{V}, \mathrm{f}=66.666 \mathrm{~Hz}$
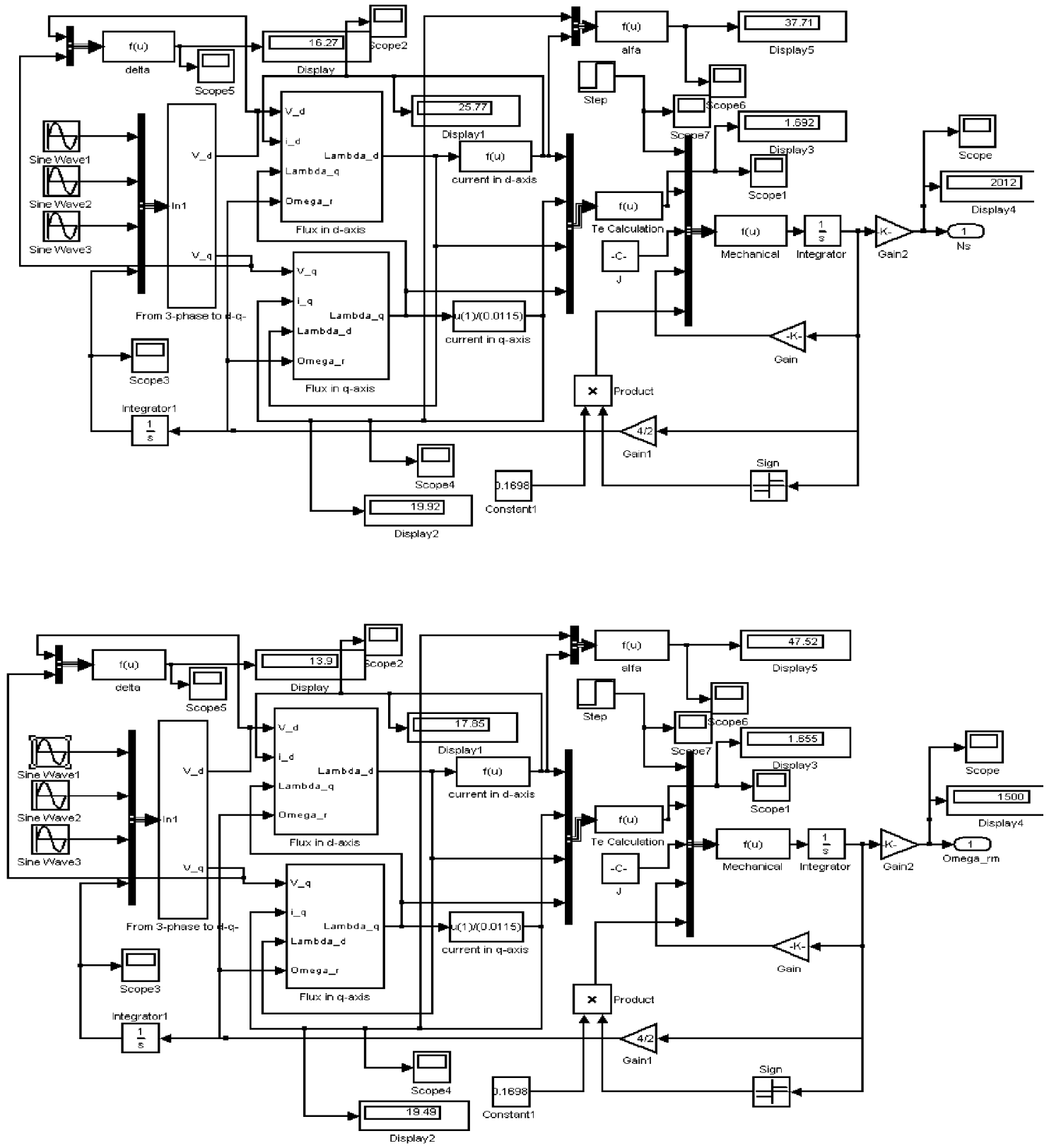

Figure (21) Dynamic simulation for SPMSM 
The above diagram show two cases for SPMSM dynamic model at $\mathrm{f}=66.666,50 \mathrm{~Hz}$, when varying the frequency with the manner of $\mathrm{V} / \mathrm{F}$ constant, it is clear that from the display of the speed that, this model gives the right values to synchronous speed.

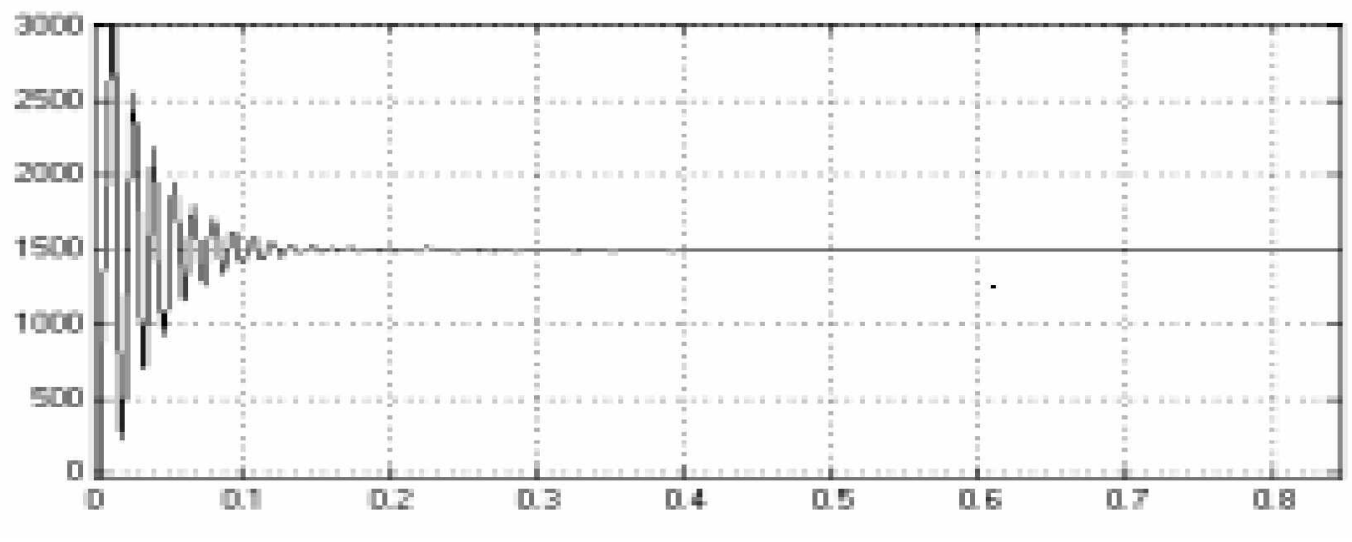

Figure (22) Speed vs time for $50 \mathrm{~Hz}$, (PMSM Model)

\section{Conclusions:}

This paper affirms on the validity of simulink in matlab environment to be used for electrical machines dynamic modelling. This paper mainly proposes simulation dynamic model for ac Interior Permanent Magnet Synchronous Motor (IPMSM), with the aid of MATLAB - Simulink. The modeling procedures are described and simulation results are presented. It is notified that, the dynamic model capable of predicting the machine's behaviour for this machine type. The effect of taking core loss in consideration in modelling is clear by showing how torque ripple will be more less than without taking it. The dynamic models are developed by coupling electrical equations and mechanical equations of the PMSM. All simulation results are presented for all machine's variable characteristics. The validity of our model here is verified using $\mathrm{V} \backslash \mathrm{f}$ control, at various frequencies values.

\section{References:}

[1] T. Sebastian, G. Slemon, and M. Rahman, "Modelling of permanent magnet synchronous motors," Magnetics, IEEE Transactions on, vol. 22, pp. 1069-1071, 1986. [2] T. M. Jahns, G. B.Kliman, and T. W. Neumann, "Interior Permanent-Magnet Synchronous Motors for Adjustable-Speed Drives," Industrial Applications, IEEE Transactions on, vol. IA-22, pp. 738-746, 1986.

[3] P. Pillay and R. Krishnan, "Modeling of permanent magnet motor drives," Industrial Electronics, IEEE Transactions on, vol. 35, pp. 537-541, 1988. 
[4] P. Pillay and R. Krishnan, "Modeling, simulation, and analysis of permanent-magnet motor drives. I. The permanent-magnet synchronous motor drive," Industry Applications, IEEE Transactions on, vol. 25, pp. 265-273, 1989.

[5] S. Morimoto, Y. Tong, Y. Takeda, and T. Hirasa, "Loss minimization control of permanent magnet synchronous motor drives," Industrial Electronics, IEEE Transactions on, vol. 41, pp. 511-517, 1994.

[6] A. H. Wijenayake and P. B. Schmidt, "Modeling and analysis of permanent magnet synchronous motor by taking saturation and core loss into account," 1997.

[7] K. Jang-Mok and S. Seung-Ki, "Speed control of interior permanent magnet synchronous motor drive for the flux weakening operation," Industry Applications, IEEE Transactions on, vol. 33, pp. 43-48, 1997.

[8] B. K. Bose, Modern power electronics and AC drives: Prentice Hall, 2002.

[9] B. Cui, J. Zhou, and Z. Ren, "Modeling and simulation of permanent magnet synchronous motor drives," 2001.

[10] C. Mademlis and N. Margaris, "Loss minimization in vector-controlled interior permanent-magnet synchronous motor drives," Industrial Electronics, IEEE Transactions on, vol. 49, pp. 1344-1347, 2002.

[11] X. Jian-Xin, S. K. Panda, P. Ya-Jun, L. Tong Heng, and B. H. Lam, "A modular control scheme for PMSM speed control with pulsating torque minimization," Industrial Electronics, IEEE Transactions on, vol. 51, pp. 526-536, 2004.

[12] R. E. Araujo, A. V. Leite, and D. S. Freitas, "The Vector Control Signal Processing blockset for use with Matlab and Simulink," 1997.

[13] C.-m. Ong, Dynamic Simulation of Electric Machinery using Matlab/Simulink: Prentice Hall, 1998.

[14] H. Macbahi, A. Ba-razzouk, J. Xu, A. Cheriti, and V. Rajagopalan, "A unified method for modeling and simulation of three phase induction motor drives," 2000.

[15] J. H. Reece, C. W. Bray, J. J. Van Tol, and P. K. Lim, "Simulation of power systems containing adjustable speed drives," 1997.

[16] S. Onoda and A. Emadi, "PSIM-based modeling of automotive power systems: conventional, electric, and hybrid electric vehicles," Vehicular Technology, IEEE Transactions on, vol. 53, pp. 390-400, 2004. 